\title{
ARTIGO
}

dO https://doi.org/10.22481/praxisedu.v16i38.6009

\section{RELAÇÕES ENTRE O PÚBLICO E O PRIVADO NA EDUCAÇÃO BRASILEIRA: UMA REFLEXÃO SOBRE O FUTURE-SE}

\author{
RELATIONS BETWEEN THE PUBLIC AND THE PRIVATE IN BRAZILIAN \\ EDUCATION: A REFLECTION ON THE FUTURE-SE
}

\section{RELACIONES ENTRE PÚBLICO Y PRIVADO EN LA EDUCACIÓN BRASILEÑA: UNA REFLEXIÓN SOBRE EL FUTURE-SE}

\author{
Jonas Tarcísio Reis \\ Centro Universitário Metodista - Brasil \\ Jorge Luiz Ayres Gonzaga \\ Centro Universitário Metodista - Brasil
}

Maria Raquel Caetano

Instituto Federal do Sul-Rio-Grandense - Brasil

\begin{abstract}
Resumo: Este artigo busca analisar, no contexto do capitalismo contemporâneo, alguns movimentos no âmbito da política educacional do atual governo federal dedicando-se ao recente programa Future-se, destinado à educação superior. Tal análise é realizada a partir da revisão histórica do avanço do capitalismo, especialmente na América Latina, com foco no Brasil. Os eixos do programa são abordados, em especial o que trata das Organizações Sociais, cuja tendência se configura como mecanismo de subsídio público a instituições geridas por organismos privados como uma alternativa de gestão para a educação pública brasileira. No desenvolvimento metodológico, procedemos ao levantamento e à análise de fontes primárias (documentos oficiais, institucionais e relatórios) e secundárias. Nas considerações, apresentamos as consequências para a educação no contexto atual.
\end{abstract}

Palavras chave: Política Educacional; Organização Social; Future-se.

\begin{abstract}
This article analyzes, in the context of contemporary capitalism, some movements within the educational policy of the current federal government dedicated to the recent program Future-se, aimed at higher education. This analysis is based on the historical review of the advance of capitalism, especially in Latin America, focusing on Brazil. The axes of the program are approached, especially the Social Organizations, whose tendency is configured as a mechanism of public subsidy to institutions managed by private organizations as a management alternative for Brazilian public education. In the methodological development, we proceeded to the survey and analysis of primary
\end{abstract}


sources (official, institutional documents and reports) and secondary sources. In the considerations, we present the consequences for education in the current context.

Keywords: Educational politics; Social organization; Future-se.

Resumen: Este artículo busca analizar, en el contexto del capitalismo contemporáneo, algunos movimientos dentro de la política educativa del gobierno federal actual dedicados al programa reciente Future-se, dirigido a la educación superior. Este análisis se basa en la revisión histórica del avance del capitalismo, especialmente en América Latina, centrándose en Brasil. Se abordan los ejes del programa, especialmente las Organizaciones Sociales, cuya tendencia se configura como un mecanismo de subsidio público a las instituciones administradas por organizaciones privadas como una alternativa de gestión para la educación pública brasileña. En el desarrollo metodológico, se procedió a la encuesta y análisis de fuentes primarias (documentos e informes oficiales, institucionales) y fuentes secundarias. En las consideraciones, presentamos las consecuencias para la educación en el contexto actual.

Palabras clave: Política educativa; Organización social; Future-se.

\section{Introdução}

No início do século XXI, o Brasil viveu um período de esperança. Essa esperança esteve fundamentada na possibilidade de se ultrapassar dificuldades históricas da nossa sociedade. Essas dificuldades estavam - e ainda estão relacionadas - a desigualdade social estabelecida desde a sua conquista no período colonial, aos interesses de uma elite nobiliárquica no período imperial, em uma subordinação aos barões da produção cafeeira paulista na República Velha ${ }^{1}$. A tentativa de virada nesta política econômica e social é realizada por Getúlio Vargas que, com todas suas idiossincrasias, promoveu o processo incipiente de industrialização no Estado Novo e é nesse período que surgem as concepções de escola pública, sobretudo com Anísio Teixeira. O processo de industrialização é estancado com a morte de Getúlio em 1954, retomada com Jucelino Kubitschek. A tentativa de superação das desigualdades históricas construídas no Brasil é a projetada pelas "Reformas de Base" propostas por Jango, que culminou com o golpe civil-militar de 1964. Após a redemocratização do Brasil, cristalizado com a denominada "Constituição Cidadã de 1988”, o país tem sua democracia restituída, entretanto, a economia fica subordinada, sobremaneira, ao

\footnotetext{
${ }^{1}$ Com a Revolução de 1930, o governo de Getúlio Vargas procurou desenvolver o Brasil em direção a industrialização e a independência econômica da monocultura cafeeira evidenciada na política do "café com leite", que consistia no revezamento ao poder central entre presidentes paulistas e mineiros. O irônico, mas compreensível é perceber que o golpe de 2016 foi engendrado e posto em prática por um mineiro que tinha perdido as eleições e a elite paulista que sempre viu o restante do Brasil como seu quintal.
} 
capital externo e ao neoliberalismo nos governos Sarney, Collor, Itamar e de Fernando Henrique Cardoso.

Somente com os governos de Luiz Inácio Lula da Silva e, com menos intensidade, no primeiro governo Dilma é construída uma política de distribuição de renda e do desenvolvimento econômico brasileiro sob a perspectiva de campo de independência da esfera estadunidense. Devemos destacar, que os governos do Partido dos Trabalhadores não significaram uma ruptura com o capitalismo e com o liberalismo (CASTELO, 2013; CARVALHO, 2018), como hoje procuram demonstrar as forças conservadoras e reacionárias. Esse aspecto, aliado a ascensão de governos de viés popular na Paraguai, Argentina, Uruguai, Equador, Bolívia e, sobretudo, na Venezuela fizeram os Estados Unidos da América, o sistema rentista mundial e os neoliberais voltarem seus olhos novamente para América Latina. Esse processo de autonomia procurado por nações latino-americanas desencadearam um movimento de estancamento desse processo pelas elites do capital internacional em consonância com os interesses econômicos, políticos e culturais de nossa "elite do atraso" (SOUZA, 2017).

No contexto internacional, as relações entre o capital - a sua expressão do neoliberalismo e no Brasil do governo Bolsonaro o avanço do neoliberalismo proposto por Paulo Guedes (Ministro da Economia do Governo Bolsonaro), formado na Escola de Chicago - e os Estados Nacionais deixam bem claras as políticas das nações colonizadoras sobre as nações colonizadas. Esses processos de "Colonialidad" são expressos por diversos autores de matizes teóricas e conceituais diferentes bem como as variadas formas de interpretação desta realidade. Entretanto, autores como Chomsky (2017a, 2017b, 2013), Wallerstein (2002a, 2002b), Harvey (2013) e Mészáros (2008) apontam a relação do capitalismo na execução das políticas econômicas e sociais em todo o mundo e com características específicas de conquista (territorial ou não), exploração e dominação cultural sobre as nações em desenvolvimento.

Harvey (2013), analisando as relações sobre o conceito de Modernidade e PósModernidade, deixa claro que essa discussão nos encaminha para a compreensão de que a Modernidade não esgotou seu processo histórico do desenvolvimento humano. $\mathrm{O}$ autor debate a partir de Marx e afirma que:

Marx descreve, pois, processos sociais que agem no capitalismo caracterizados por promover o individualismo, a alienação, a fragmentação, a efemeridade, a inovação, a destruição criativa, o desenvolvimento especulativo, mudanças imprevisíveis nos métodos de produção e de consumo (desejos e necessidades), mudança da experiência e do espaço e do 
tempo, bem como uma dinâmica de mudança social impelida pela crise. (HARVEY, 2013, p. 107).

Assim sendo, o pensador evidencia que o modo de produção capitalista sofreu mudanças em sua organicidade, porém, elas não abrangeram as estruturas essenciais de sua organização produtiva na sua infraestrutura e superestrutura. Características que levam ao consumo e ao individualismo ainda permanecem intactas na esfera dos "desejos e das necessidades". A lógica explorativa sobre as nações subdesenvolvidas ou em desenvolvimento continua a mesma, ou seja, acesso a matéria prima barata, mercado consumidor e, sobretudo, mão de obra barata. A diferença crucial, segundo o autor, é que o modo de produção capitalista ultrapassa o modelo taylorista-fordista e se constitui, na atualidade, sob o fundamento da flexibilização. Conforme Harvey: "foram abertas arenas de conflito entre Nação-Estado e o capital transnacional comprometendo a fácil acomodação entre grande capital e grande governo tão típico da era fordista" (HARVEY, 2013, p. 160). Ou seja, na atualidade a relação entre Estado Nacional e o capital produtivo e, acima de tudo, o capital financeiro especulativo influenciam de maneira profunda e indelével as economias nacionais, como o Brasil, que acabam por interesses do capital externo e interno se colocando como apêndice do sistema econômico mundial.

Neste contexto, o capitalismo elaborou o conceito de "globalização". Não podemos esquecer que ao longo da história todas as economias imperiais procuraram. de uma forma ou de outra. expandir seu acesso às riquezas por meio do comércio ou conquista. Em nossa compreensão, o "globalismo" defendido ardorosamente pelas nações desenvolvidas e centradas na "Colonialidad", procura em primeira ordem quebrar as fronteiras territoriais e alfandegárias para escoar sua produção, explorar as riquezas materiais e humanas dos países conquistados e explorados. Essa prática de "globalização" é assim analisada por Mészáros (2004):

Consequentemente, seria necessário admitir abertamente que o alardeado processo de "globalização" é uma ficção tendenciosa e conservadora - um conceito usado apenas quando se ajuste à conveniência ideológica retrógrada de alguém (como acontece atualmente em inúmeras ocasiões) -, ou se teria de deixar aberta a questão dos desenvolvimentos históricos futuros da alternativa hegemônica do trabalho à ordem sociometabólica do capital. (MÉSZÁROS, 2004, p. 33).

Em síntese, a globalização é uma falácia imposta ideologicamente aos países em desenvolvimento como uma panaceia para todos os males do não desenvolvimento material e espiritual de um grupo social. Prossegue o autor destacando que: 
Por isso, tanto é grotesco projetar a difusão universal das condições materiais favoráveis dos países capitalistas altamente privilegiados - que, na verdade, para garantir seus privilégios, apoiam-se pesadamente na continuação da dependência estrutural e da miséria dos outros - , como sugerir que mudanças potenciais que afetem negativamente o trabalho nos países capitalistas dominantes não possam ocorrer ou, se ocorreram, não são importantes [...] (MÉSZÁROS, 2004, p. 33-34).

Essa configuração capitalista permanece asfixiando os países subdesenvolvidos e em desenvolvimento em detrimento aos países ricos do norte do globo. Aliás, sempre se procura definir a prosperidade das nações do norte como se fossem consequências das potencialidades de seus povos e das riquezas materiais de suas nações. Não podemos desconsiderar de Quijano (2010), no contexto em que destaca uma fala de Pizarro solicitando ajuda ao governador do Panamá, que lhe é negada, afirma que:

Em efecto, el grupo armado llega a la Isla del Gallo y quiere forzar a Pizarro a regresar com toda su diezmanda tropa a Panamá. Pero Pizarro mostro allí quién era. Se niega a regressar, saca su espada, traza uma raya em la arena de la islã, la cruza hacia el Sur, y lanza su famosa arenga: <<Por allí, al norte, los que quieran ser pobres. Por aqui, al Sur, los que quieran ser ricos > [...] (QUIJANO, 2010, p. 07).

Com a conquista, a exploração e a colonização material e imaterial das riquezas das Américas enriqueceu as nações do norte e empobreceu as nações do sul. Onde havia riqueza e fartura a conquista, a exploração e a colonização das nações do norte levou as do sul a um processo de dependência e miséria que perdura até os dias atuais com a pressão política, econômica e ideológica como ficou evidente nas interferências do Estados Unidos da América do Norte na política interna de nações como o golpe parlamentar no Paraguai. também na ascensão do ultraliberalismo que levou a Argentina a profunda crise econômica que vive, as tentativas de desestabilização do governo boliviano de Evo Morales, no governo do equatoriano de Rafael Correa, no eterno bloqueio a Cuba e no golpe parlamentar-jurídicomidiático contra o governo legitimamente eleito da presidenta Dilma Rousseff e contra todas as conquistas populares e, principalmente, sobre a "educação" como demonstra o governo neoliberal e conservador de Jair Bolsonaro.

Para corroborar nossa concepção de que os interesses do capitalismo industrial e, principalmente, rentista têm sobre o Brasil, traremos mais dois autores que trabalham a influência dos Estados Unidos da América sobre o mundo contemporâneo e, sobretudo, acerca da América Latina e Caribe. Conforme Chomsky (2017a): 
[...] Na última década, pela primeira vez em quinhentos anos, a América do Sul deu passos auspiciosos para se libertar da dominação ocidental. A região tomou a iniciativa de rumar na direção da integração e começou a atacar alguns dos terríveis problemas internos das sociedades regidas por elites predominantemente europeizadas, minúsculas ilhas de extrema riqueza num mar de miséria [...]. (CHOMSKY, 2017a, p. 100).

Essa iniciativa tomada por países da América Latina e Caribe não agradaram os colonizadores modernos. Para eles, a subordinação aos seus interesses é fundamental à transferência de riquezas materiais e humanas. Nossas nações da latino-américa parecem que sofrem da síndrome da conquista, exploração e colonização permanentes. Nossas elites econômicas são cooptadas (ou compradas por meia dúzia de "moedas de prata") de diversas formas para que vendam as riquezas naturais do continente, o trabalho e a vida das pessoas.

Exemplo cristalino desta exploração sistêmica das nações do norte em relação às nações do sul é a tentativa desesperada que o capital internacional e o nacional, este subordinado ao primeiro, construíram no Brasil a falácia de que os problemas econômicos e sociais do país seriam resolvidos com a Reforma Trabalhista e a Reforma da Previdência. Essas reformas, segundo os liberais e neoliberais, desentravariam o setor produtivo, aliadas a venda do patrimônio público ${ }^{2}$. Essa fórmula já foi posta em prática e não resolveu os problemas da economia brasileira em outros tempos.

Para finalizarmos esta reflexão sobre as relações do capitalismo mundial e os reflexos na sociedade brasileira, nos ancoramos em Wallerstein (2002a, 2002b). O autor aborda a crise profunda em que vive o capitalismo e as possibilidades de superação desse modo de produção. Wallerstein afirma que o modo de produção capitalista não conseguiu e não conseguirá superar seus antagonismos e as consequências nefastas que provoca nas sociedades e na natureza. Como causas dos entraves que o capitalismo não conseguiu superar, o pensador destaca a constituição e o fim do Estado de Bem Estar Social, que funcionou no pós guerra e a partir da década de 1970 foi sistematicamente destruído e as manifestações do Maio de 1968 que colocaram em xeque o modo de produção capitalista. Segundo a autor:

O liberalismo não desapareceu em 1968, mas perdeu, isto sim, seu papel de ideologia definidora da geocultura. Nos anos 70, o leque ideológico voltou a

\footnotetext{
${ }^{2}$ Em relação a venda do patrimônio público este foi e é o maior engodo realizado sobre a população brasileira. Nos governos Sarney, Collor de Mello e Fernando Henrique Cardoso foram dilapidadas frações significativas do patrimônio público a preços de "bananas" com financiamento estatal e a economia não melhorou. No estado do Rio Grande do Sul o governo de Antonio Brito vendeu tudo que era possível e renegociou a dívida pública com a União e levou o Estado a insolvência. No atual governo de Eduardo Leite, do PSDB, a voracidade para vender o patrimônio público é impressionante, e o mais apavorante é que vai vender empresas de alta tecnologia e superavitárias. No linguajar popular sul-rio-grandense se afirma que Eduardo Leite vai vender a vaca e depois vai comprar leite, queijo e requeijão.
} 
ser uma verdadeira tríade, acabando com a distinção em que ficaram imersas as três ideologias quando se tornaram apenas três variações concretas do liberalismo, entre 1850 e os anos 60 de nosso século. (WALLERSTEIN, 2002b, 145).

Isso pode explicar o porquê do recrudescimento do pensamento conservador ultraliberal que se instalou no Brasil. A falta de perspectiva do próprio liberalismo fez com que ele se entregasse, momentaneamente ou não, nos braços do conservadorismo populista de espectro fascista. Para o capital rentista mundial e nacional não importa qual o regime de governo a nação possui. Seu interesse fundamental é a garantia de que terá apoio e incentivo para implementar sua política econômica e frações significativas do nosso empresariado industrial prefere aferir ganhos significativos no mercado financeiro ao invés do produtivo: a famosa e decrépita "Elite do Atraso" como nos demonstrou Souza (2017).

Uma questão que pode ser levantada, a partir de Wallerstein (2002a), é a necessidade do liberalismo conservador se alicerçar no conceito de paternalismo, ou seja, na tutela da sociedade pelo capital, pela mão invisível do capital e pela meritocracia esvaziando, desta maneira, todo e qualquer historicidade do desenvolvimento humano. A postura paternalista do liberalismo parece um paradoxo. Entretanto, quando vemos todas as regulações que o capitalismo liberal necessita como monopólios, oligopólios, reservas de mercado dos recursos estatais obtidos através da arrecadação de impostos para inversão no próprio capital etc., percebemos que o liberalismo é uma falácia tanto no campo político como econômico. Segundo o autor:

[...] Na verdade, os liberais não se opuseram ao conceito de aristocracia per $s e$, mas à ideia de que os aristocratas sejam pessoas definidas por certos sinais externos de status, derivados de realizações passadas de um ancestral, de títulos que outorgam privilégios. Em sua teorização, o liberal, nesse sentido, é extremamente voltado para o presente. É a realização do individual que interessa o liberal, pelo menos teoricamente [...] (WALLERSTEIN, 2002a, p. 130).

Assim, o desejo liberal não é acabar com os privilégios da aristocracia e suprimi-los da sociedade. O objetivo liberal é se apossar dos privilégios da aristocracia criando a ideologia de meritocracia dissociada da história individual e social. Nessa linha reflexiva, afirma que:

[...] Os aristocratas, os melhores, são na verdade, só podem ser, os que provaram no presente que são os mais competentes. Isso se expressa pelo uso no século XX do conceito de "meritocracia", como legitimação definidora da hierarquia social. (WALLERSTEIN, 2002a, p. 130-131).

Neste contexto, tanto o aristocrata quanto o liberal querem possuir privilégios em relação a população como totalidade. $\mathrm{O}$ aristocrata fundamenta seus privilégios na herança da 
posição de nascimento transferida de pai para filho. Já o liberal acredita que seus privilégios estão associados de maneira intrínseca ao seu mérito de superar dificuldades. Ambos, aristocratas e liberais, se utilizam de uma retórica ideológica para manter seus privilégios econômicos, políticos e sociais. Os aristocratas estão desaparecendo, mas a ideologia de merecer por serem "os melhores", ou seja, "aristói” permanece aferrado a ideologia burguesa.

Os elementos teóricos e conceituais supracitados procuram contribuir para a compreensão do momento atual da realidade brasileira desde o golpe de 2016, que culminou com a deposição da presidenta Dilma Rousseff, do processo autoritário e ilegal que se abateu sobre o presidente $\mathrm{Lula}^{3}$, que culminou com o cerceamento do preceito constitucional de somente ser possível condenar um cidadão após o processo transitar em todas as instâncias judiciais.

\section{A política educacional do atual governo (2019-2022) e a desconstrução da educação pública no Brasil}

A educação em uma sociedade de classes não é construída de maneira equilibrada, racional e igualitária na aplicação dos recursos materiais e imateriais para a formação humana. Os estudos realizados ao longo dos primeiros anos deste século e, quase que na totalidade do século XX, demonstraram a desigualdade com que a educação é distribuída para a população brasileira. Talvez o fato que represente melhor esse aspecto é compararmos duas sociedades americanas que tiveram suas economias e sociedades fundamentadas no sistema escravocrata, Estados Unidos da América e Brasil. Para termos uma ideia, a Educação Básica nos EUA foi universalizada no século XIX e no Brasil isso somente aconteceu na década de 1990, portanto, um século depois. Atualmente, os Estados Unidos se tornou o berço das privatizações na educação, utilizando desde vouchers, terceirizações e privatização por dentro e por fora da escola pública. Um exemplo são as "charters schools" em que a educação permanece pública, mas a gestão é realizada por instituições privadas. Segundo Adrião (2014), as escolas são públicas, gratuitas e gozam de independência frente às normativas curriculares e às exigências trabalhistas ditadas pelos distritos às escolas públicas tradicionais.

\footnotetext{
${ }^{3}$ A fatos de domínio público que se tornaram cristalinos ao demonstrarem os interesses das elites que vinham perdendo as eleições nos últimos dezesseis anos (16) consecutivamente e que provavelmente perderiam as eleições de 2018 se Lula fosse candidato. Prova disso, para não nos estendermos muito, foi a perseguição realizada pela grande mídia monopolizada, pela famosa conversa do senador Romero Juca afirmado que "o golpe era com o Congresso, as Forças Armadas e o STF e culminando na nomeação sem o menor pudor do exjuiz Sérgio Moro para o Ministério da Justiça.
} 
Ainda conforme a autora, "os graus de independência são variáveis e as equipes gestoras ou proprietárias dessas escolas podem ser fortemente responsabilizadas quando o desempenho previsto e/ou as metas determinadas pelo distrito deixam de ser cumpridas" (ADRIÃO, 2014, p. 241).

Há muito tempo as forças populares vêm exigindo e lutando pelo direito à educação. O primeiro movimento significativo foi realizado pelos "pioneiros", tendo como expoente Anísio Teixeira. Outro grande momento da educação brasileira advenho das contribuições teóricas e metodológicas construídas por Paulo Freire, que se mostraram originais, complexas e profundas em relação a outras teorias educacionais espalhadas pelo mundo. Hoje, nesse momento de quase irracionalidade generalizada, vemos atônitos ataques às concepções elaboradas por Paulo Freire, que são reverenciadas e aplicadas em todo o planeta. Entretanto, não podemos descolar os fatos que acontecem nesse momento difícil em que a educação é atacada como se fosse o maior mal de uma sociedade com assertivas de autores que já citamos anteriormente.

Mészáros (2008) afirma que: "No reino do capital, a educação é, ela mesma, uma mercadoria (MÉSZÁROS, 2008, p. 16). Essa compreensão nos remete ao fato de que a educação é uma mercadoria que pode ser comprada e conforme o poder aquisitivo do comprador ele pode ter acesso a uma educação de melhor ou pior qualidade. Essa concepção mercantil segue o caminho oposto àquele proposto pelo autor que se manifesta em que: [...] "Educar es depositar em cada hombre toda la obra humana que le há antecedido; es hacer a cada hombre resumen del mundo vivente hasta al día em que vive” [...] (MÉSZÁROS, 2008, p. 58). Ou seja, educar não é treinar para desenvolver uma determinada atividade no modo de produção capitalista. Educar não é produzir processos de alienação que tenham como objetivo mascarar a realidade vivenciada por nós humanos. Educar é construir a possibilidade de transformação da natureza e das relações sociais sob a égide da felicidade humana e não da exploração humana.

[...] Se os elementos progressistas da educação formal forem bem-sucedidos em redefinir a sua tarefa num espírito orientado em direção à perspectiva de uma alternativa hegemônica à ordem existente, eles poderão dar uma contribuição vital para romper a lógica do capital, não só no seu próprio e mais limitado domínio como também na sociedade como um todo. (MÉSZÁROS, 2008, p. 59).

Neste sentido, a educação deveria romper com a finalidade do utilitarismo que o capital lhe atribui. Muito se questiona sobre a educação pública e sua qualidade em função de 
sua enorme dificuldade de valorização dos professores, perspectiva dos estudantes em prosseguir os estudos, infraestrutura das escolas e outros tantos aspectos relevantes. Porém, nos questionamos se a educação nas instituições privadas não é alienante ao ponto de somente formarem mão de obra necessária à reprodução do capital. Formação esta que se dá, sem dúvida, em profissões valorizadas, mas sem aquilo que Mészarós nos indicou acima.

Outra análise que impacta profundamente é a exposta por Chomsky (2013). Conforme o autor:

Os desenvolvimentos descritos por você são todos eles parte de um grande esforço para desmantelar completamente a educação pública, essencialmente privatizando-a. O poder privado não gosta de educação pública, por muitas razões. Uma delas é o princípio em que ela se fundamenta, que ameaça o poder. A educação pública baseia-se num princípio de solidariedade. Assim, por exemplo, meus filhos nasceram cinquenta anos atrás. No entanto, eu sinto e devo sentir que deveria pagar impostos para que as crianças do outro lado da rua possam ir à escola [...] (CHOMSKY, 2013, p. 41).

Se essa solidariedade for quebrada não existirá sentimento que una um ser humano com o outro. É aí que se situa a concepção de meritocracia. É colocar nas costas dos indivíduos toda a responsabilidade do chamado fracasso escolar quando na verdade ele nunca teve a oportunidade concreta e real de superar os obstáculos presentes em sua vida. Para o capital, essa responsabilização individual é um dos elementos mais importantes da ideologia e da alienação da realidade concreta. Continua o pensador:

[...] Isso vai de encontro a doutrina de que só devemos apenas cuidar de nós mesmos e deixar todo o resto de lado, um princípio fundamental da lei dos negócios. A educação pública é uma ameaça a esse sistema de crenças, pois se fundamenta num senso de solidariedade, comunidade e apoio mútuo. (CHOMSKY, 2013, p. 41).

Essa abordagem podemos colocar também na proposta de aposentadoria por capitalização proposta pelo neoliberal Paulo Guedes. Por um lado, o sistema financeiro ganha ao controlar a poupança do trabalhador sem mediação do Estado. Por outro lado, como nos demonstrou o pesquisador, a solidariedade daqueles que pagam os benefícios dos aposentados atuais se esgota em relação àqueles trabalhadores que entrarão no mercado de trabalho e solidariamente contribuiriam para a aposentadoria daqueles que já deram sua contribuição social por intermédio do trabalho. Podemos perceber que o sistema capitalista, embasado em uma pretensa ideologia liberal, procura "amarrar todas as pontas da teia de aranha" para que o estudante e, posteriormente, o trabalhador não possam escapar dessa armadilha odienta e cruel. O indivíduo fica imóvel a espera que o grande Leviatã venha devorá-lo. É nesse 
contexto apresentado que abordaremos as reformas na educação que o atual governo federal vem tentando implementar, inviabilizando o direito à educação pública para a classe trabalhadora.

\section{O processo de desmonte da educação pública: atuais retrocessos}

As reformas educacionais, em curso no Brasil, como parte de uma agenda global estruturada para a educação (DALE, 2004; SALBERG, 2012), redefinem as formas de compreender a gestão da educação e da escola. Isso porque introduzem novos elementos, como a parceria público-privado, a gestão por resultados, o voluntariado, a filantropia, a terceirização e, também, o que chamamos de 'formas de privatização', trazendo implicações à educação e à escola. Atualmente, instituições neoconservadoras também vêm atuando no sentido de influenciar o conteúdo das propostas educacionais pelo meio da elaboração de leis que visam cercear o direito à educação e seu processo pedagógico.

Ao mesmo tempo em que os processos de privatização têm avançado na educação brasileira, as políticas sociais têm sido consideradas "inimigas do governo através de construções ideológicas dirigidas ao senso comum e sentenciam que as 'despesas obrigatórias' nos gastos sociais assegurados pela Carta de 1988 são o principal desestabilizador do equilíbrio fiscal" (FAGNANI, 2017, p. 02). Afirmam ainda que sem a revisão do pacto social da democratização não haverá solução para a estabilidade da dívida pública. "Em última instância, quando deliberam que o País não cabe no PIB, estão dizendo que as demandas sociais da democracia não cabem no orçamento" (FAGNANI, 2017, p. 03). E as políticas sociais em uma democracia só fazem sentido se for para atender os ditames da população, ou seja, "a democracia é entendida como luta por direitos e as políticas sociais como a materialização de direitos sociais" (PERONI; OLIVEIRA; FERNANDES; 2009, p. 763).

Ao assumir o governo, em março de 2019, o presidente Jair Bolsonaro anunciou o corte de pelo menos 30\% no financiamento da Rede Federal de Ensino. O decreto 9.741, publicado em 29.03.2019 na edição extra do Diário Oficial da União, contingenciou R\$ 29,582 bilhões do Orçamento Federal de 2019. Com isso, a Educação perdeu R\$ 5,839 bilhões, cerca de $25 \%$ do previsto. Somados os cortes, as pastas da Educação, Saúde e Cidadania tiveram R \$ 7,5 bilhões de verbas congeladas (ANDES,2019, s/p). São R\$ 2,4 bilhões que estavam previstos para investimentos em programas da educação infantil ao 
ensino médio que foram bloqueados. As universidades federais sofreram cortes de $\mathrm{R} \$ 2,2$ bilhões até o momento. O Programa Ciência sem Fronteiras deixou de existir em 2017 e, atualmente, o Programa Idioma sem Fronteiras foi extinto. Os cortes atingem também a CAPES, a Educação de Jovens e Adultos (EJA), a educação de Portadores de Necessidades Especiais (PNE) e, em contrapartida aos cortes, foi anunciada a assinatura de um termo de cooperação técnica com o Instituto Ayrton Senna para medidas voltadas a educação básica (BRASIL, 2019).

A educação como regra em toda a história do Brasil, não é poupada dos desmontes institucionais. Pelo contrário, após o golpe político-jurídico-midiático de 2016, em que a oposição e as forças hegemônicas associadas às forças neoconservadoras, não conseguiam assumir o poder político via eleitoral para que o processo de desmantelamento do Estado brasileiro fosse retomado e aprofundado, iniciou-se a entrega de todos os serviços públicos para a iniciativa privada4. A propagação de Instituições de Ensino Superior (IES) da rede privada alcançou índices de crescimentos elevadíssimos neste período. Das 2.448 Instituições de Ensino Superior registradas no Brasil em 2017, 75,3\% são privadas e 24,7\% são públicas, conforme a Tabela 1.

Tabela 1 - Número de ingressantes em Cursos de Graduação, por modalidade de ensino e categoria administrativa-2017:

\begin{tabular}{|c|c|c|c|c|c|c|}
\hline \multirow{3}{*}{ Estatísticas Básicas } & \multicolumn{6}{|c|}{ Categoria Administrativa } \\
\hline & \multirow{2}{*}{ Total Geral } & \multicolumn{4}{|c|}{ Pública } & \multirow{2}{*}{ Privada } \\
\hline & & Total & Federal & Estadual & Municipal & \\
\hline Número de Instituiçōes & 2.448 & 296 & 109 & 124 & 63 & 2.152 \\
\hline \multicolumn{7}{|l|}{ Educação Superior - Graduação } \\
\hline Curso $^{1}$ & 35.380 & 10.425 & 6.353 & 3.487 & 585 & 24.955 \\
\hline Matrícula & 8.286 .663 & 2.045 .356 & 1.306 .351 & 641.865 & 97.140 & 6.241 .307 \\
\hline Ingresso Total & 3.226 .249 & 589.586 & 380.536 & 181.665 & 27.385 & 2.636 .663 \\
\hline Concluinte & 1.199 .769 & 251.793 & 151.376 & 83.951 & 16.466 & 947.976 \\
\hline
\end{tabular}

Fonte: INEP/ MEC, 2017.Dados: Censo do Ensino Superior 2017.

Em 10 anos, entre 1980 e 2017 (GRÁFICO 1), a matrícula nas IES privadas aumentou e têm uma participação de $75,3 \%(6.241,307)$ no total de matrículas de graduação. A rede pública, portanto, participa com 24,7\% (2.045.356). A rede privada tem três de quatro alunos

\footnotetext{
${ }^{4}$ Não nos resta menor dúvida que empresa privada somente vai investir em empresas estatais (construídas com recursos públicos) que produzam grandes lucros e poucos riscos. Essas empresas financiadas pelo capital social público na compra de empresas constituídas com recursos públicos são um grande negócio. Entretanto, como qualquer produto no sistema capitalista, as populações que não possuem alta densidade de consumo, como acontece com a telefonia e acontecia com a energia elétrica e ultimamente com o Programa Mais Médicos nos demonstrou, ficarão sem dúvidas sem acesso a esses serviços.
} 
de graduação. Segundo o Censo, em 2017, a matrícula na rede pública cresceu 2,8\% e a matrícula na rede privada cresceu 3\% após a queda registrada em 2016. Entretanto, destacamos que o tripé ensino, a pesquisa e a extensão é realizado na sua maioria, nas universidades públicas.

Gráfico 1 - Número de Matrículas em Cursos de Graduação por categoria administrativa1980-2017:

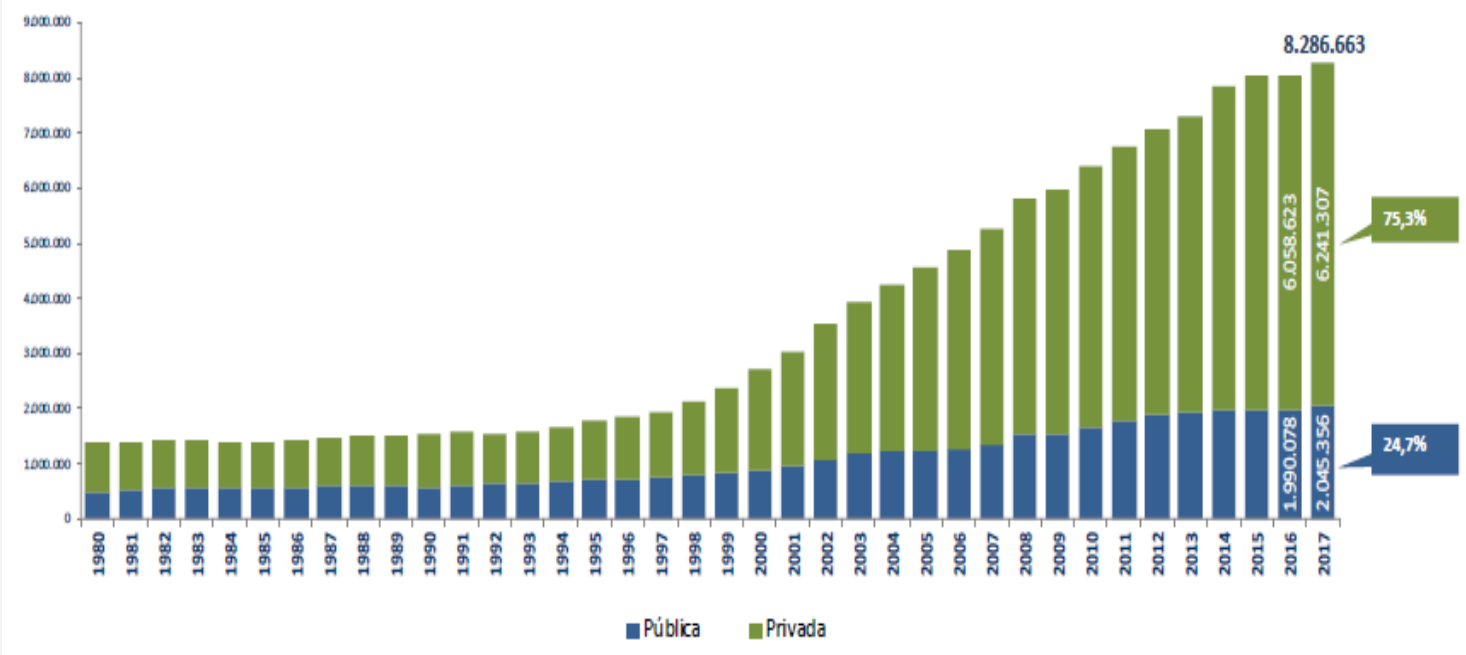

Fonte: INEP/ MEC, 2017.Dados: Censo do Ensino Superior 2017.

É possível observar que a maioria dos ingressantes no Educação Superior se deu fundamentalmente pela via privada, realizando a compra da educação que deveria ser um direito, portanto, gratuito. Mesmo quando tomamos para análise o período recente, com a expansão das Instituições de Educação Superior (IES) em que milhares de excluídos entraram e formaram-se nas universidades públicas, a tendência de predomínio do privado sobre o público se reforçou.

A Tabela 1 e o Gráfico 1 evidenciam, também, a distribuição das matrículas no setor privado e no público, bem como registram o crescimento anual total e por setor. Os dados são por demais instrutivos quanto ao argumento de que não houve mudança substantiva na expansão do número de matrículas nas IES públicas ao longo do tempo. Os dados da tabela 1 e do gráfico 1 indicam que há uma demanda crescente de Educação Superior, razão porque as matrículas aumentaram tanto. Essa demanda é, todavia, respondida, fundamentalmente, pela iniciativa privada. A tendência caracterizada pelo predomínio do privado sobre o público se mantém em todo o período. 
Porém, garantias legais foram instituídas a partir da promulgação da Lei $\mathrm{n}$. 12.711/2012, que dispõe sobre o ingresso nas universidades federais e nas instituições federais de ensino técnico de nível médio que estabelece cotas de no mínimo 50\% das vagas de instituições públicas federais para estudantes que cursaram o ensino médio integralmente em escolas públicas. Dentre essas vagas, $50 \%$ são reservadas a estudantes oriundos de famílias com renda igual ou inferior a um salário e meio per capita. Igualmente, são reservadas vagas aos candidatos autodeclarados pretos, pardos e indígenas, em proporção igual à sua distribuição nas unidades da Federação em que são localizadas as instituições federais de ensino superior ${ }^{5}$.

\section{A educação superior foi ao mercado: o Programa Future-se}

Apesar das contradições, foram nos governos Lula (2003-2011) e Dilma (2011-2016) que ocorreu a maior ampliação do número de alunos no Ensino Superior em função das políticas de acesso e permanência nas instituições públicas como apresentamos na seção anterior. Embora os dados apresentados e a evolução do número de alunos nas instituições públicas, foi nas instituições privadas que ocorreu o maior número de matrículas.

Não obstante, no dia 17 de julho de 2019 o governo federal lançou o Programa Future-se, que aposta na reestruturação do financiamento de institutos e universidades federais. O programa, segundo o MEC, tem como objetivo central estimular que as instituições operem para captar suas receitas próprias, condição que seria possível ao estabelecerem contratos com Organizações Sociais (OSs) e atuarem dentro de alguns modelos de negócios privados. Professores, movimento estudantil, associações, sindicatos docentes e movimentos sociais do campo educacional reagiram com preocupação ao lançamento do programa.

Conforme o PL que institui o Programa Institutos e Universidades Empreendedoras e Inovadoras - FUTURE-SE:

O Programa Institutos e Universidades Empreendedoras e Inovadoras (FUTURE-SE) tem por finalidade o fortalecimento da autonomia administrativa, financeira e de gestão das Instituições Federais de Ensino Superior (Ifes), por meio de parceria com organizações sociais e do fomento à captação de recursos próprios. (FUTURE-SE, MEC, 2019).

\footnotetext{
${ }^{5}$ Outros programas destinados ao acesso em instituições privadas (IES) é o Universidade para Todos (PROUNI) que prioriza os estudantes que não possuem condições financeiras para arcar com os custos das mensalidades do curso, podem concorrer a bolsas integrais ou parciais em IES privadas dependendo da nota alcançada no Exame Nacional do Ensino Médio (ENEM). O Financiamento Estudantil (FIES) consiste no subsídio a graduação de estudantes matriculados em IES privadas com conceitos positivos no Sistema Nacional de Avaliação do Ensino Superior (SINAES), possibilitando ao estudante financiar seu curso.
} 
Apresenta três eixos que embasam o Programa: I - gestão, governança e empreendedorismo; II - pesquisa e inovação; e III - internacionalização. A participação no programa dar-se-á por adesão, no prazo estabelecido em regulamento, mediante assinatura de termo de adesão. Ao aderir ao FUTURE-SE, as IFES se comprometem conforme Artigo $2^{\circ}$ do PL:

I - utilizar a organização social contratada para o suporte à execução de atividades relacionadas aos eixos previstos no $\S 1^{\circ}$ do art. $1^{\circ}$, desenvolvidas nos institutos e nas universidades federais;

II - adotar as diretrizes de governança dispostas nesta Lei, inclusive ao Sistema de Governança a ser indicado pelo Ministério da Educação; e III - adotar programa de integridade, mapeamento e gestão de riscos corporativos, controle interno e auditoria externa.

$\S 1^{\circ}$ A permanência da IFES no programa está condicionada à manutenção dos requisitos dispostos no caput, sem prejuízo da observância ao art. 16 da Lei $n^{\circ} 9.637$, de 1998, e a exclusão do programa pode ensejar a aplicação de penalidades. (FUTURE-SE, MEC, 2019).

Em um primeiro momento, o que parece mais evidente é a possibilidade de contratação das Organizações Sociais, "qualificadas" pelo governo para ter acesso ao recurso público. Segundo a minuta do projeto de lei de criação do programa, as OSs terão como atribuição, além de apoiar a execução de atividades vinculadas aos três eixos do programa, a de apoiar a execução de planos de ensino, pesquisa e extensão, gerir recursos relativos a investimentos em empreendedorismo, pesquisa, desenvolvimento e inovação e também auxiliar na gestão patrimonial dos imóveis das instituições participantes do programa.

O programa visa facilitar e ampliar uma prática que hoje já existe para captação de recursos pelas universidades, que são as parcerias público-privadas para o desenvolvimento de pesquisas e projetos específicos, segundo o ministro da educação.

\section{Organizações Sociais e o Marco Regulatório}

Em relação às Organizações Sociais (OS), lembramos que surgiram no governo de Fernando Henrique Cardoso, por ocasião da Reforma Administrativa do Estado, elaborada por Bresser Pereira. É um modelo de organização pública não-estatal destinado a atividades publicizáveis mediante qualificação específica. É uma forma de propriedade pública não-estatal, constituída pelas associações civis sem fins lucrativos, que não são propriedade de nenhum indivíduo ou grupo e estão orientadas diretamente para o atendimento do interesse público. As OS 
são um modelo de parceria entre o Estado e a sociedade. O contrato de gestão é o instrumento que regula as ações das OSs (MARE, 1997, p.13).

Qualificada como Organização Social, a entidade estará habilitada a receber recursos financeiros e a administrar bens e equipamentos do Estado. Em contrapartida, ela se obrigará a celebrar um contrato de gestão, por meio do qual serão acordadas metas de desempenho que assegurem a qualidade e a efetividade dos serviços prestados ao público. (MARE, 1997, p.14).

As OSs foram caracterizadas à época como entidades de direito privado e se aproximam na sua gestão, cada vez mais, às praticadas no setor privado, o que deverá representar, entre outras vantagens: a contratação de pessoal nas condições de mercado; a adoção de normas próprias para compras e contratos; e ampla flexibilidade na execução do seu orçamento (MARE, 1997, p.13).

Após mais de quinze anos de vigência da legislação que regulamentou as OSs, foi instituído o Marco Regulatório das Organizações da Sociedade Civil - MROSC, que estabelece o regime jurídico das parcerias voluntárias firmadas entre a administração pública e as organizações da sociedade civil em regime de mútua cooperação. A Lei 13.019/2014, alterada pela Lei 13.204/2015, define como deve ser a relação jurídica do Poder Público, em suas esferas federal, estadual e municipal, com as OSCs, especialmente nos casos de transferências de recursos para a execução de projetos de interesse público.

O MROSC assimila de vez a ideia de que o 'convênio' é um instrumento jurídico inadequado para regular as relações entre OSCs e entes públicos e introduz o 'Termo de Fomento' e o 'Termo de Colaboração'. A diferença entre os dois instrumentos refere-se ao objeto da pareceria. Na maior parte dos casos, o Termo de Colaboração aplica-se à execução de uma atividade de caráter continuado, frequentemente resultante da implementação de uma área de política pública já estruturada e bem parametrizada, enquanto o Termo de Fomento aplica-se ao desenvolvimento de um projeto, de uma ação cujos contornos, alcances e metodologias ainda não estejam bem definidos e para a qual possam existir muitas formas possíveis de execução. (MEDEIROS; MACHADO, 2017, p. 40)

Importante ressaltar que a lei estabelece mecanismos específicos para a celebração de parcerias, em que entidades maiores ou melhor estruturadas se articulam com outras organizações com menor capacidade operacional e técnica em um esforço conjunto para a realização de uma determinada atividade em parceria com a administração pública, criando uma rede como forma de atuação, o que já acontece no Brasil, co-existindo os financiadores e os parceiros técnicos, que oferecem todo tipo de serviços a esfera pública. 
O terceiro setor, além de regulamentado (OS/Lei 9.790 de 23/03/99, OSCIP/ Lei 9.790 de 23/03/99) se consolidou com a aprovação do Marco Regulatório, alterado em 2015 pela Lei 13.204, que estabelece o regime jurídico das parcerias voluntárias firmadas entre a administração pública e as organizações da sociedade civil em regime de mútua cooperação, e define a relação jurídica do governo com as OSC - Organizações da Sociedade Civil.

É através dessa legislação que o MEC pretende transformar as universidades e institutos federais em instituições privatizadas, cujo discurso é dar autonomia para as IFES. Contudo, o que se quer é utilizar a organização social contratada para o suporte à execução de atividades relacionadas aos eixos de gestão, governança e empreendedorismo; pesquisa e inovação; e internacionalização como o próprio programa estabelece. Ao que parece, é substituir orçamento público pelo empreendedorismo privado.

Roberto Leher (2019), em recente manifestação sobre o Future-se, aponta que o programa modifica 16 leis, que são as Leis: 8.010/1990, 8.032/1990, 8.313/1991, 8.248/1991, 9.249/1995, 9.250/1995, 9.394/1996, 9.532/1997, 9.637/1998, 9.991/2000, 10.735/2003, 10.973/2004, 11.196/2005, 12.550/2011, 12.772/2012, 13.243/2016. Ainda, conforme Leher:

A amplitude do disposto nestas leis confirma que está em curso uma mudança substantiva no marco legal da Educação Superior (LDB), da ciência e tecnologia (importações, informática e automação, inovação tecnológica, marco legal), comercialização de energia elétrica, cultura (Pronac, lei de incentivo à cultura), de normas tributárias (imposto de renda, Lei do Bem, lucros auferidos no exterior, regime especial de tributação para a plataforma de exportação de T.I.), organizações sociais (lei das OS, Projeto de Interesse Social), carreira do magistério do ensino superior, EBSERH. (LEHER, 2019, s/p).

Em breve análise realizada sobre o Future-se, percebe-se que o elemento central do programa é o mecanismo pelo qual a gestão da universidade se desloca do Estado para as corporações empresariais. Com isso, o governo reduz as verbas das IFES, os currículos, as pesquisas, diminuindo financiamento através dos contingenciamentos e abrindo a possibilidade de financiamento para as grandes corporações empresarias, seja através de mecanismos de doação, de parcerias público-privadas, constituição de fundos do mercado financeiro e/ou de capitais privados. Esses mecanismos transferem a dimensão pedagógica e cultural para os interesses de grandes empresas para que a universidade trabalhe segundo os interesses das corporações doadoras. Esse é um dos arcabouços de suposta autonomia financeira, para atuarem como empresas independentes, geridas pelas OSs, privatizando a gestão das universidades e colocando a serviço das grandes corporações. 
Igualmente na lógica da autonomia financeira, poderá cobrar mensalidades, implementando uma proposta de privatização da gestão, do financiamento e sua orientação pedagógica. Ou seja, não privatiza a propriedade da universidade, mas privatiza a lógica da sua existência. Será a universidade orientada para o mercado como quer a nova ordem mundial ou como descreve Harvey (2011, p.178):

[...] a mercadificação que pressupõe a existência de direitos de propriedade sobre os processos, coisas e relações sociais, supõe que se pode atribuir preço a eles e negociá-los nos termos de um contrato legal [...]". [...] "equivale a atribuir um preço a coisas que na verdade jamais foram produzidas como mercadorias" (idem, p. 179).

Isso implica o Estado abrir mão da educação e "terceirizar" a educação pública. Assim sendo, o Estado e a sociedade deixam de ajudar a formar seus cidadãos para que a iniciativa privada o faça. $\mathrm{O}$ alerta em relação a disputa entre a iniciativa privada e a educação pública pela construção dos processos educacionais e seus recursos foi sinalizado por Azevedo (2007). Segundo o autor:

No sistema educacional, a cultura da mercantilização faz-se presente pela tentativa de introduzir na escola os valores e a linguagem empresarial. Produtividade, qualidade total, vantagens corporativas, centros de excelência, bem como outros termos de uso básico no vocabulário de mercado [...]. Formar cidadãos clientes e consumidores, portadores da cultura de mercado, passou a ser tarefa primordial da escola [...] (AZEVEDO, 2007, p. 99).

O pesquisador coloca em evidência quais são as necessidades estabelecidas pelo mercado. Se por um lado um dos objetivos de escola sob a ótica neoliberal é formar "cidadãos clientes", por outro lado como nos demonstra Frigotto (2012, 2010), Saviani (2007) e Kuenzer (2014) é inegável a relação entre trabalho e conhecimento e, portanto, os processos da Educação Formal, Não Formal e Informal (GOHN, 2010). Neste sentido, a relação entre o modo de produção capitalista e as formas de educação são inseparáveis. Saviani (2007, p. 152), nos demonstra que "Trabalho e educação são atividades especificamente humanas. Isso significa que, rigorosamente falando, apenas o ser humano trabalha e educa”. Isso significa afirmar a condição humana de transformar a natureza e as relações sociais.

Desta maneira, o trabalho transcende a esfera produtiva e se explicita plenamente na dimensão ontológica. Frigotto (2010) também se orienta nesse sentido. Segundo a autor: "Por ser o trabalho o pressuposto fundante do devenir humano, ele é o princípio educativo e, portanto, é fundamental que todo ser humano, desde a mais tenra idade socialize esse 
pressuposto" (FRIGOTTO, 2010, p. 34). Em suma, o trabalho humano deve ser articulado como princípio educativo não para preparar para inserção no mercado de trabalho, mas para que possa se desenvolver a dimensão da cidadania e solidariedade.

Kuenzer (2014) caminha nessa mesma direção. Segunda a autora as contradições e o antagonismo do modo de produção capitalista se expressam nas relações do "Mundo do Trabalho"6 e na educação. Possuindo como objeto a formação de professores nas relações da educação com o capitalismo, a autora afirma que:

[...] Se no capitalismo há projetos educacionais antagônicos, no bojo das relações sociais e produtivas não há um projeto único, ou neutro na formação de professores, independentemente do nível, da etapa ou da modalidade de educação que seja analisada. (KUENZER, 2014, p.78).

Portanto, aquilo que acontece no modo de produção capitalista expressado pelo neoliberalismo e estabelecido pela política econômica do governo atual e colocada em prática pelo ministro da esfera econômica, que é oriundo do sistema financeiro, deixa cristalina a contradição entre essa proposta de desenvolvimento econômico - que até agora se anunciou por nenhuma política de desenvolvimento, estando somente alicerçada na reforma da previdência como panaceia para todos os males do Brasil. A política do atual governo se expressa como se a privatização e o Estado Mínimo fossem a solução para todos os males. Nem nos países desenvolvidos essa política neoliberal foi colocada em prática como nos observa Wallerstein (2002). Segundo o autor:

Para bem apreciar a importância do sistema de Estados para o capitalismo, é preciso começar pelo fato de que os capitalistas não são, e nunca foram, hostis ao sistema de Estados. A possibilidade de acumular capital, que é a essência do capitalismo, depende dos Estados, e seria impossível se os Estados não existissem ou se enfraquecessem a ponto de serem apenas o Estado "guarda noturno" hipotético [...] (WALLERSTEIN, 2002, p. 10).

Nesse sentido, acreditamos que o capitalismo precisa do Estado não para desenvolver o bem estar das pessoas como foi no período pós-guerra do Estado de Bem Estar Social. Na atualidade, o capitalismo precisa, acima de tudo, que o Estado retire recursos da população e transfira para que o capital consiga continuar a sua incessante acumulação de riquezas em detrimento do trabalho. Neste contexto, o capitalismo necessita do Estado, mas como bem dizem os neoliberais, o Estado tem que ser pelo menos o mínimo para as classes populares.

\footnotetext{
${ }^{6}$ Geralmente se confunde o conceito de "mundo do trabalho" com o conceito de "mercado de trabalho". O primeiro visa conhecer as relações que envolvem e substantivam as relações de transformação dos seres humanos com a natureza e os indivíduos. Mercado de trabalho é a formação direcionada às exigências do modo de produção capitalista.
} 


\section{Considerações Finais}

Tentamos demonstrar a estreita relação entre o contexto mundial e, em particular, o ocidental e a influência do capitalismo como forma hegemônica de produção de riquezas e de maneira como se articula a construção e permanência do Brasil sob a influência estadunidense. Prova dessa condição é o lugar de subordinação em que o Brasil foi colocado em relação aos Estados Unidos da América do Norte. Outros sintomas são nossa política externa de alinhamento incondicional aos interesses norte-americanos e $\mathrm{o}$ fato do representante máximo - talvez, nessa condição, mínimo - de nossa nação desdenhar nosso povo em terras estrangeiras. Isso talvez, junto com as problemáticas econômicas e das recentes reformas, especialmente na Educação Superior, que procuramos evidenciar, desnude aquilo que Souza (2017) denominou como a "Elite do Atraso" e a condição que nossas elites possuem em relação aos outros povos e a si mesma: seu complexo indelével de inferioridade.

Os movimentos governamentais atuais no Brasil, bem como a correlação de forças existente na nação têm sinalizado muito mais a educação como uma mercadoria do que como um direito a ser garantido para toda a população. Os caminhos da exacerbação da privatização e terceirização no âmbito educacional parecem estar cada vez mais pavimentados. Observamos isso principalmente quando os fóruns, as instituições representativas e os debates entre as lideranças do Estado brasileiro, que são responsáveis direta ou indiretamente pelo direcionamento e a formulação de políticas educacionais, se pautam muito mais em organismos internacionais e no que o empresariado propõem do que nas necessidades reais da construção de uma educação de qualidade social majoritariamente.

O campo do financeirismo na educação e daqueles que defendem a privatização da educação de forma mais agressiva têm crescido. Aqueles que se constituíram ao longo dos últimos 30 anos como personagens que interferiram nas políticas de Estado, objetivando maiormente a realização de políticas públicas e privadas, têm ganhado força enorme no ditame das políticas propostas pelo Ministério da Educação do atual governo. O discurso utilizado não só pelo atual ministro da educação, como dos demais que o antecederam neste mesmo governo, tem colocado a luta pela combate ao monopólio estatal na educação como meta. Este é o discurso central dos novos neoliberais que estão formulando e impondo uma série de medidas governamentais do ponto de vista da influência ideológica.

Nesse conjunto de ações do Ministério da Educação, o programa Future-se busca o aprofundamento das relações do governo com o setor privado da educação bem como com 
empresas que têm no campo da educação uma nova fonte de manutenção ou obtenção das suas taxas de lucro. Dessa forma, podemos analisar o forte alinhamento das políticas do governo aos ditames mercadológicos que têm orientado a economia e passam agora a orientar a forma de organização e oferecimento da educação pública brasileira.

Nesse processo, contudo, temos visto a reorganização de setores dos movimentos sociais, como estudantil e docente, no sentido da realização de atos públicos, palestras, eventos, conferências, seminários e fóruns de debate objetivando a denúncia, o combate e a crítica ao Programa Future-se, bem como às demais ações adjacentes do Ministério da Educação no sentido, muitas vezes, da Defesa do Plano Nacional de Educação e das políticas existentes de financiamento, fomento e manutenção das instituições federais de ensino.

O "fardo de nosso tempo histórico" é o desmonte da ciência, da educação estatal e do setor público. Apesar de alguns ainda tentarem sustentar um modelo moral conservador para o país em seus discursos, suas práticas anti-desenvolvimentistas com o dinheiro público permanecem. Atualmente, a cada 3 estudantes, 2 entraram nas instituições públicas pelo sistema de cotas por etnias ou oriundos de escolas públicas. A universidade pública finalmente começou a abraçar a classe média baixa e pobre desse país nos governos anteriores. Por isso, os elitistas querem o fim das cotas, querem o estrangulamento das políticas de assistência das instituições federais ao reduzir seu financiamento, além de controlar a gestão das IES. A resistência e a ascensão da classe trabalhadora na defesa da educação pública e de qualidade para os trabalhadores é urgente, para reafirmar a educação como direito e não como mercadoria.

\section{REFERÊNCIAS}

ADRIÃO. Theresa. Escolas charters nos EUA: contradições de uma tendência proposta para o Brasil e suas implicações para a oferta da Educação pública. Revista Educação e Filosofia, Uberlândia, v. 28, n. especial, p.263-282, 2014.

AZEVEDO, José Clovis. Reconversão cultural da escola: mercoescola e escola cidadã. Porto Alegre: Editora Universitária Metodista, 2007.

BRASIL. Lei No 12.711, DE 29 DE AGOSTO DE 2012. Dispõe sobre o ingresso nas universidades federais de ensino técnico de nível médio e dá outras providencias. Disponível em http://www.planalto.gov.br/ccivil_03/_ato2011-2014/2012/lei/l12711.htm. Acesso 2 agosto 2019.

CARVALHO, Laura. Valsa brasileira: do boom ao caos econômico. 1 ed. São Paulo: Todavia, 2018. 
CASTELO, Rodrigo. O social-liberalismo: auge e crise da supremacia burguesa na era liberal. 2 ed. São Paulo: Expressão Popular, 2013.

CHOMSKY, Noam. Quem manda no mundo? 1 ed. São Paulo: Planeta, 2002a.

CHOMSKY, Noam. Réquiem para o sonho americano: os 10 princípios de concentração de riqueza \& poder. 1 ed. Rio de Janeiro: Bertrand Brasil, 2002b.

CHOMSKY, Noam. Sistemas de poder: conversas sobre as revoltas democráticas globais e os novos desafios do Império americano. 1 ed. Rio de Janeiro: Apicuri.

FAORO, Raymundo. Os donos do poder. Porto Alegre: Globo, 1958.

FRIGOTTO, Gaudêncio. Educação e a crise do capitalismo real. 6 ed. São Paulo: Cortez, 2010 .

GOHN, Maria da Glória. Educação não formal e o educador social: atuação no desenvolvimento de projetos sociais. São Paulo: Cortez, 2010.

HARVEY, David. Condição pós-moderna. 24 ed. São Paulo: Loyola, 2013.

HOLANDA, Sérgio Buarque de. Raízes do Brasil. 15 ed. Rio de Janeiro: José Olympio, 1982.

KUENZER, Acácia Zeneida. Dilemas da formação de professores para o Ensino Médio no século XXI. In:. AZEVEDO, José Clovis; REIS, Jonas Tarcísio (Org.). O ensino médio e os desafios da experiência: movimentos da prática. 1 ed. São Paulo: Moderna/Santillana, 2014.

LEHER. Roberto. Análise preliminar do Future-se indica a refuncionalização das universidades e Institutos Federais. Disponível em

https://avaliacaoeducacional.files.wordpress.com/2019/07/sobre-o-future-se-notas-prelimrleher-24-07pdf.pdf . Acesso em 25 jul de 2019.

MEDEIROS. Rogério de Souza; MACHADO. Nínive Fonseca. O novo marco regulatório das organizações da sociedade civil e uma nova agenda de pesquisa sobre as relações entre órgãos de controle, as organizações da sociedade civil e os gestores públicos. Revista de Ciências Sociais, n. 46, Janeiro/Junho de 2017, p. 23-47.

MÉSZÁROS, István. Educação para além do capital. 2 ed. São Paulo: Boitempo, 2008.

MÉSZÁROS, István. O poder da ideologia. São Paulo: Boitempo, 2004.

PRADO Jr., Caio. Formação do Brasil contemporâneo. 1 ed. São Paulo: Companhia das Letras, 1995.

QUIJANO, Aníbal. La crisis del horizonte de sentido colonial/modeno/eurocentrado. Revista Casa de Las Américas. Nos. 259-260. abril/septembre. p. 04-15. 
RIBEIRO, Darcy. O povo brasileiro: a formação e o sentido do Brasil. São Paulo: Companhia das Letras, 1995.

RIBEIRO, Darcy. Teoria geral do Brasil. 2 ed. Rio de Janeiro: Civilização Brasileira, 1975

RIO GRANDE DO SUL. Governador recebe Jonathan Hage, criador das charters schools nos EUA. Disponível em: https://www.estado.rs.gov.br/governador-recebe-jonathan-hage-criadordas-charters-schools-nos-eua Acesso em 21/05/2019.

SAVIANI, Demerval. Trabalho e educação: fundamentos ontológicos e históricos. Revista Brasileira de Educação. p. 152-165. v. 12 n. 34 jan/abr. 2007.

SOUZA, Jessé. A classe média no espelho: suas histórias, seus sonhos e ilusões, sua realidade. Rio de Janeiro: estação Brasil, 2018.

SOUZA, Jessé. A elite do atraso: da escravidão a Lava Jato. Rio de Janeiro: Leya, 2017.

WALLERSTEIN, Immanuel. Após o liberalismo: em busca da reconstrução do mundo. Petrópolis: Vozes, 2002b.

SOUZA, Jessé. O fim do mundo como o concebemos: ciência social para o século XXI. Rio de Janeiro: Revan, 2002a.

\section{SOBRE OS AUTORES:}

\section{Jonas Tarcísio Reis}

Doutor em Educação pela Universidade do Vale do Rio dos Sinos (UNISINOS). Atua no Centro Universitário Metodista (IPA). Integra o Grupo de Pesquisa Educação e Inclusão no IPA. E-mail: jotaonas@yahoo.com.br

iD http://orcid.org/0000.0001.6748.2225

\section{Jorge Luiz Ayres Gonzaga}

Doutor em Educação pela Universidade La Salle (UNILASALLE). Integra o Grupo de Pesquisa Educação e Inclusão no Centro Universitário Metodista (IPA). E-mail: jl.ayresgonzaga@yahoo.com.br

\section{iD http://orcid.org/0000.0001.8511.7221}

\section{Maria Raquel Caetano}

Doutora em Educação pela Universidade Federal do Rio Grande do Sul (UFRGS). Docente no Mestrado em ProfEPT no Instituto Federal do Sul-Rio-Grandense (IFSul) e docente no Campus Sapucaia do Sul. Integra o Grupo de Pesquisa Relações entre o Público e o Privado na Educação -GPRPPE na UFRGS. Coordena a pesquisa "Gestão Democrática no IFSul". Email: caetanoraquel2013@gmail.com

iD http://orcid.org/0000-0001-6973-908X 